\title{
Exploring the Police Support Volunteer Experience: Findings from a National Survey
}

Matthew Callender ${ }^{1 *}$, Melissa Pepper $^{2}$, Kathryn Cahalin $^{1}$, Iain Britton ${ }^{1}$

${ }^{1}$ Institute for Public Safety, Crime and Justice, University of Northampton, UK

${ }^{2}$ Department of Sociology, University of Surrey, $U K$

* Corresponding Author

Email: matthew.callender@northampton.ac.uk

Telephone: 01604893304

Address: Institute of Public Safety, Crime and Justice, University of Northampton, Boughton Green Road, Northampton, NN2 7AL 


\section{Exploring the Police Support Volunteer Experience: Findings from a National Survey}

There are an estimated 8,000 Police Support Volunteers (PSVs) in England and Wales, contributing around 650,000 hours each year to an expanding variety of tasks to support their local constabularies. Despite this, the evidence base around the experiences of being a PSV is remarkably limited. Drawing on findings from the first national survey of police volunteers in England and Wales, undertaken in early 2016 with just over 1,000 PSV responses, this article explores key factors that are associated with the overall experience of being a PSV pointing towards the significance of management, support, supervision, connection, contribution and development on volunteer morale. The article sets these findings within the strategic context of future developments for PSVs, considers practical actions for improving volunteer experience, and highlights the importance of further research into being a volunteer in policing.

Keywords: Police Support Volunteers; national survey; experience; morale; strategy.

\section{Introduction}

Citizens have assumed a prominent role in the delivery of policing since before the development of organised law enforcement, with the Special Constabulary having deep historical roots (Bullock 2014, Gill and Mawby 1990, Emsley 1996). In the context of this long history, the Police Support Volunteer (PSV) is a relatively recent addition, with the first programme commencing in Kent in 1992 (Bullock 2014). Whereas Special Constables are volunteer members of the public who when on duty wear a uniform and have full police powers, PSVs are volunteers who perform tasks that complement the duties of police officers and staff. While the majority of policing roles are carried out by paid professionals, the volunteer continues to occupy a space within the complex and shifting nature of contemporary policing, in which services are delivered by a 
combination of actors (Millie 2016, Bullock 2014). Compared to other aspects of the 'extended police family', relatively little is known about PSVs, their experiences within the police organisation, and the impact of these experiences on their sense of morale as volunteers. Given the number of PSVs, the sizeable quantities of hours served and range of activities undertaken this gap in knowledge is a critical one. By demonstrating key factors impacting upon the morale of PSVs, this paper will inform the approaches taken by police forces to develop their volunteering programmes. Better understanding what influences the morale of PSVs also aids the improvement of support provided for volunteers, improving the volunteer experience and impacting upon retention and effectiveness.

In 2016, efforts to systematically collate data at a national level estimated that there were just over 8,000 PSVs across forces in England and Wales (a number which had not grown particularly in recent years) (Britton et al. 2016a), contributing approximately 650,000 hours of voluntary activity a year (Wilkins 2008). The roles undertaken by PSVs across policing are wide-ranging (Unison 2014), encompassing hundreds of different role descriptions nationally across a breadth of different aspects of policing (Britton et al. 2016a). The nature of police volunteering varies widely, with the breadth of roles neither universal nor consistent, and indeed limited in some force contexts.

The emergence and development of PSVs over the past twenty-five years reflects several key policy and practice drivers across the wider backdrop against which policing is evolving. The policing landscape has altered significantly, most notably via growing diversity of those who 'do policing'. Through recognition of the limited capacity of the formal state owned criminal justice system to control crime alone, mounting public demands to address fear of crime and quality of life issues, and 
increasing financial burden on the public purse, a "pluralised, fragmented and differentiated patchwork" of state and non-state actors started to take the place of a singular and monopolistic police service (Crawford 2008, p. 147, Rogers 2012). An array of individuals beyond the uniformed constable - including the PSV - are now playing a role in policing, law enforcement, and community safety (Stenning 2009, Bullock 2014).

The context in which police organisations operate is also changing fast. As the 'modus operandi' of crime and criminals continues to move into complex transnational and technology enabled terrains, and demands from citizens for more reassurance and security in neoliberal states show no signs of slowing, policing organisations are faced with new challenges in defining their 'mission' and the way they 'deliver business' (Bullock 2014, Jones and Newburn 2006, Zedner, 2003). The ability of policing services to face these challenges arguably will depend on their willingness to embrace the "fullest advantages of the opportunities that a pluralised approach can offer" (Stenning and Shearing 2015, p. 7) and "adapt to a context in which they are no longer perceived as the monopolistic provider" (Crawford 2008, p. 175). Indeed, organisations and individuals beyond the traditional police services (including PSVs), with their potential to draw in new skills, experience, capacity and capability, may be at the forefront of helping to meet these challenges (Britton and Knight 2016, Britton and Callender 2018).

Looking more broadly across the delivery of public services as a whole, recognition of the strategic importance of voluntarism - although by no means a new concept - features notably in mainstream political discourse and social policy (Gaskin and Smith 1995, Cabinet Office 2008, Rochester et al. 2010, Finnegan and Brewis 2012, Zimmeck 2012). Citizen involvement resonates closely with dominant narratives 
across policing and wider public policy of legitimacy, effectiveness, capacity building, inclusion, cohesion, community, and collective civic engagement (Johnston 2003, Ren et al. 2006, Casey 2008, Giangrande et al. 2008, Gravelle and Rogers 2009a, Steden et al. 2011, Morgan 2012, Bullock 2014). In a climate of increasingly scarce resources, economic drivers also feature prominently in this landscape, particularly in reference to an unpaid (although by no means cost-free) volunteer resource. PSV respondents to Bullock's (2017, p. 346) study reflected on the utilisation of volunteers as a "pragmatic response to economic reality" with warranted police officers increasingly focused on crime fighting and global security, meaning others - including volunteers - are establishing delivery positions across the broader activities of policing (Ren et al. 2006, Gravelle and Rogers 2009b, COPS 2011, Phillips 2013, O’Neill 2014, Stenning and Shearing 2015, Millie 2016).

\section{Police Support Volunteers as Ambiguous, Contested and Peripheral}

Volunteers in policing occupy an ambiguous and contested space, with the role arguably considered as 'peripheral' and 'precarious' in the policing arena (Gill and Mawby 1990, p. 144, Britton and Knight 2016). This is perhaps reflective of a paradigm of 'regularcentrism' within policing, where the role, contribution and potential of those who volunteer sit outside of mainstream strategic and academic discourse on policing and police reform (Britton and Callender 2018). While PSVs have evolved across all forces in England and Wales (albeit not exclusively under a standardised title), the role has received limited policy direction or practice guidance at national level, lacks consistency around definition and scope and, with the absence of specific legislative framework, local policy and practices vary widely (Britton et al. 2016a). Whilst PSV roles can (to a degree) be 'defined' by characteristics of direction and vetting by police organisations, in reality there are somewhat blurred boundaries between PSVs as a 
specific construct, and wider voluntarism and civil society activity in and around policing, public safety, and criminal justice.

There is also an increasingly prominent debate around the relationship between PSVs and paid police staff, with assertions that volunteering should provide 'additionality', rather than be central to, or supplementing, the delivery of core policing services (Bullock, 2017). A report produced by Unison (2014, p. 3 \& p. 8) referred to "volunteer mission creep", expressing concern that PSVs were being "quietly recruited" to replace police staff cuts, undertaking roles that looked "remarkably like established police staff posts". Such tensions framing volunteer contribution alongside that of paid staff are not unique to policing. Various researchers (Sherr 2008, Brudney and Meijs 2014) have explored the historical relationship between volunteers and paid staff in a social work context, highlighting tensions arising from organisational and practice change, perceptions of occupational threat to paid staff, and the ambiguous position of voluntarism within wider quests for professional status.

The often-tenuous relationship between volunteers and the paid workforce is compounded within the police organisation - an environment traditionally and culturally characterised by uncertainty, danger, authority, suspicion, social isolation, group loyalty, and apathy towards 'others' (Paoline 2003, Loftus 2010, Reiner 2010, Myhill and Bradford 2013, Phillips 2013, van Caem et al. 2013). Against this backdrop, there is often resistance towards the police engaging in approaches and activity that risk colliding with dominant cultural typologies of what it means to be a police officer (Cosgrove 2016), or which are seen to serve to diminish the image of the crime fighter with such roles derided as 'not real police work' (Loftus 2010, Jones 2010 cited in Phillips 2013). Active citizenship and wider civil involvement through volunteering requires 'buy in' from the police, both at strategic and individual officer level where 
police work is both directly controlled and delivered (Myhill 2006, Gravelle and Rogers 2009a, Carr 2012, p. 405). Members of the community are not always, however, regarded as natural partners with the police (Myhill and Bradford 2013). Steden et al. (2011, p. 446) posited that police officers "tend to try to keep their distance from citizens" and where the public are involved are often sceptical about what they can achieve, doubtful about motivations for involvement, and frustrated with issues prioritised which may not fit with traditional policing roles (Millie and Bullock 2012, Bullock and Leeney 2013).

Alongside this occupational culture context, there is argued to be a strategic leadership and policy paradigm in policing which has failed to foreground the value and role of voluntarism (Britton and Callender 2018). Bullock (2014) referred to challenges the police service face in adapting to and embracing institutional diversity, including volunteer elements, while Steden et al. (2011, p. 447) argued that civic engagement in policing "will only flourish if it receives tangible appreciation and coaching from the police and government authorities". A number of studies have shown that increased exposure to citizens and volunteers can improve views and likelihood of acceptance, socialising paid officers and staff into new ways of working and reducing the perceived threat that volunteers are sometimes seen to pose (Gravelle and Rogers 2009b, Phillips and Terrell-Orr 2013). This, however, depends on an effective framework that exposes officers and staff to opportunities to engage with volunteers in their day-to-day roles, and realise the capacity and capability that this additional resource can bring. The contested and culturally challenging space in which police volunteering exists in part accounts for the underdeveloped picture in terms of research, policy and practice, and limited realisation of the potential of volunteerism - reflected by the peripheral space it occupies within wider discourse of police reform (Britton and Callender 2018). 
Volunteering in policing is widely recognised as an under-researched area (Bullock and Leeney 2014, Pepper and Wolf 2015, Britton and Knight 2016). The role of the Police Support Volunteer has developed with little research, scrutiny or debate (Bullock 2014) and the current evidence base around the experiences of volunteers remains remarkably limited (Ren et al. 2006, Stenning 2009, Phillips 2013, Phillips and Terrell-Orr 2013, Britton and Knight 2016). Whilst there is considerable research literature and significant policy and practice in place outlining the experiences of those who work in police organisations, the clear majority is exclusively focused on paid officers and (to a lesser degree) staff. Managing and supporting volunteers presents a range of opportunities and challenges, different to those of paid staff, which policing organisations have been slow to fully appreciate and address (Britton and Knight 2016). As Cnaan and Cascio (1998, p. 2) argued "there are inherent differences between paid and volunteer work, and, therefore, findings from the vast body of literature on the organisational behaviour of paid staff are not applicable to volunteers". Similarly, Studer (2016) highlighted the importance of principles of volunteer management hinging on the distinct and unique aspects of the volunteer resource - rather than influenced by classical human resource management.

Experiences of management and support have been identified as central to volunteer morale. Again, literature in this area is largely dominated by studies conducted within a paid employment setting, with fewer focusing on the meaning that volunteers attach to morale. A range of contextual and organisational specific factors can influence morale, including leadership, collegiality, specific policy, and deployment of staff (Evans 1997). Shin and Kleiner (2003) stated that training promotes good morale and communicates to the volunteer that they are important, needed and 
appreciated. When volunteers understand the overall goal of the organisation and their role in achieving that goal, they develop self-esteem and a sense of fulfilment knowing that they have made an impact. Volunteer interest and commitment have been recognised as jointly determined by whether there is a match between the motives that are most salient for a volunteer, and the opportunity structures associated with the volunteer experience. Indeed, mismatches between volunteer expectation and experience have been linked to lower morale (Allison et al. 2002).

Morale is clearly an important factor in the management and deployment of volunteers, impacting on wellbeing and feelings towards the role. In a work-based context, high morale is typified by positive feelings and satisfaction with co-workers and how work is conducted, while low morale is characterised by bitterness, frustration, negativity, and an overall dissatisfaction with the work environment. Morale has also been linked with effective productivity or - conversely - poor morale related to lower work effort or productivity (Weakliem and Frenkel 2006). Rainman and Lippitt (1971 cited in Jamison 2003) found that poor morale was a factor that may cause volunteers to leave their organisation, together with relationships between staff members. This further highlights the importance of morale in a volunteering context, both to the experiences and contribution of volunteers, and their intention to remain within the organisation.

Distinct aspects of volunteering and volunteer management within a policing context deserve specific attention. Whilst drawing learning on volunteer experiences from beyond the policing sector is of value, this translation needs to be balanced alongside the need to adopt more contingent approaches which resist a 'false universalism' for volunteer practice and experience (Rochester 1999, Brudney and Meijs 2014). As Paull (2002, p. 25) stated, “a 'one size fits all' approach is inappropriate for volunteer management... it really does depend on the type of 
organisation". Meijs and Ten Hoorn (2008, p. 29) concurred, arguing "volunteers and the way they are organised and managed differs from context to context".

These arguments underline the importance of expanding the evidence base around PSVs. Recent legislative changes in the Policing and Crime Act 2017 in England and Wales allow chief officers to designate powers on volunteers in the same way as staff, signalling an important time in the development of PSVs. This article will draw on findings from a national survey of over 1,000 PSVs in England and Wales to explore key factors that are associated with the overall experience of being a volunteer, pointing towards the significance of management, support, supervision, connection, contribution, and development in relation to volunteer morale. The article sets these findings within the strategic context of future developments for PSVs, considers practical actions for improving volunteer experience, and highlights the importance of further research into being a volunteer in policing.

\section{Method}

The first national survey of Special Constables and PSVs across all police forces in England and Wales was undertaken by the national Citizens in Policing Community of Practice in late 2015 and early 2016 (Britton and Knight 2016). The Community of Practice was formed in June 2014 drawing together a range of stakeholders, including the College of Policing, Home Office, Association of Special Constabulary Chief Officers, National Police Chief's Council, Association of Police and Crime Commissioners, and Neighbourhood Watch, alongside leads from police forces and volunteering expertise (Citizens in Policing Community of Practice 2016). The survey content was developed following consultation across these stakeholders, and included a range of questions covering motivations, experience, ambitions, skills, history of 
volunteering, and future intentions, together with a range of personal demographic factors. The survey intended to help 'give voice' to those who volunteer in policing, and inform a new national strategy for Citizens in Policing launched in July 2016 (Citizens in Policing Community of Practice 2016).

The survey was distributed online to volunteers across each of the 43 police forces in England and Wales and the British Transport Police during December 2015 and January 2016. Distribution was managed at individual force level, on behalf of the national Community of Practice. With almost 3,000 completed responses $(1,908$ for Special Constables and 1,002 Police Support Volunteers), the survey is the largest ever undertaken across police volunteering in England and Wales with responses from every police force area. This article focuses on the results from PSVs.

There were several challenges inherent in undertaking a survey of PSVs on a national scale. As highlighted earlier in this article, there are inconsistent definitions of PSVs across police forces and variation in terms of numbers, roles, and local practice. Whilst the survey results discussed in this article provide the first national data capture of experiences across PSVs, attempts to present generalisable findings risk 'averaging out' and over-simplifying a range of locally disparate and variable pictures.

This is further complicated by uneven response rates across different forces, which likely reflects a range of factors including poor basic data management and different approaches to engaging volunteer participants across forces (Britton et al. 2016b). This impacts on forces' capabilities to effectively identify potential participants and distribute the survey to them, and serves to restrict the ability to analyse and contextualise the survey respondents against limited and unreliable data of the PSV population as a whole. Furthermore, while online survey distribution to special 
constables was strengthened by most 'Specials' regularly accessing online tasking and communication systems, for the majority of PSVs this was not the case, and consequently the online 'reach' was limited and variable. It is possible that this was further exacerbated by the demography of PSVs - who are predominantly older and may experience additional online access limitations.

Despite these challenges, the national survey provides a significant building block in the development of a stronger evidence base for police volunteering. Moreover, the results of the survey identify key areas for further research and enquiry in terms of gaining a better understanding of the factors shaping morale and the experiences of being a PSV.

\section{Description of Variables and Analytical Procedure}

Survey content was designed around seven categories relating to the experience of being a PSV: 1. Management and Supervision; 2. Training; 3. Recognition, Appreciation and Fair Treatment; 4. Making a Difference to the Community; 5. Skill Recognition and Development; 6. Flexibility and Individual Need; and 7. Feedback. Respondents were asked to score their agreement with a series of statements within each category, using a five-point Likert scale (1: 'Strongly Agree'; 2: 'Agree'; 3: 'Neither Agree nor Disagree'; 4: 'Disagree'; 5: 'Strongly Disagree'). Individual scores were recoded into the following categories: 1 and 2 'Agree'; 3 'Neither Agree nor Disagree'; 4 and 5 'Disagree'. Firstly, the breakdown of the statements by these three categories is presented in Table 2, with the proportion of the overall sample that agreed with these statements reported in the text. Secondly, the analysis explored the relationship between levels of agreement with these experiential factors (statements) and self-reported morale. Here, respondents who indicated 'Neither Agree nor Disagree' were excluded 
from the analysis, in order to create binary categorical variables. Whilst this resulted in a reduced sample size for each statement, it was necessary in order to answer the primary focus of this paper which was to explore the association between those with good and poor morale and their agreement or disagreement with a series of experiential statements. Therefore, the approach to analysing the relationship between these statements and levels of agreement with the focal statement 'I would describe my morale as being good' (also recoded into 'agree' and 'disagree'), was achieved using chisquare testing at $95 \%$ confidence level $(\mathrm{p}<0.05)$ to determine the extent to which different experiential factors were associated with overall morale.

\section{Results}

Basic demographic results of the study sample $(\mathrm{N}=1,002)$ are illustrated in Table 1. Just over half of respondents were male $(\mathrm{N}=540,54 \%)$ and the majority were White $(\mathrm{N}=$ 927, 94\%). Just under half of all participants were aged $60-74$ years $(\mathrm{N}=461,48 \%)$. Nearly a third $(\mathrm{N}=287,30 \%)$ had been a PSV for between 2 and 5 years.

\section{INSERT TABLE 1 ABOUT HERE}

The results of the survey are provided in Table 2, which includes all responses. For statements around Management and Supervision, a sizeable majority of PSVs liked and enjoyed the work they did $(\mathrm{N}=872,90 \%)$, with nearly three quarters satisfied with levels of supervision received in relation to the amount of support needed $(\mathrm{N}=686$, 72\%). Just over half of PSVs surveyed stated that the force was good at managing volunteers $(\mathrm{N}=532,56 \%)$.

Within Training, just under two thirds of respondents indicated that their initial training was enough to be effective when they began their volunteering role $(\mathrm{N}=659$, 
69\%). A little over half of respondents agreed that they received sufficient ongoing training to remain effective in their role $(\mathrm{N}=506,53 \%)$.

Statements relating to Recognition, Appreciation and Fair Treatment, presented a high proportion of PSVs who agreed that they felt fairly treated as a volunteer $(\mathrm{N}=$ $836,88 \%$ ). Around three quarters of respondents agreed that their efforts as a volunteer were well recognised $(\mathrm{N}=706,74 \%)$ and felt appreciated by the police service for the work and impact they made $(\mathrm{N}=706,74 \%)$.

Within Making a Difference to the Community, a vast majority of respondents agreed that they had made a difference to their local police service $(\mathrm{N}=869,89 \%)$. A smaller proportion - just under two-thirds - felt they had made a difference to their community $(\mathrm{N}=605,63 \%)$, while fewer still $(\mathrm{N}=370,40 \%)$ indicated that they had helped to tackle crime or anti-social behaviour in their community.

Statements around Skill Recognition and Development received positive yet less favourable responses compared to other categories, with around half of respondents indicating their local force understood and utilised their skills and experience $(\mathrm{N}=497$, $53 \%)$, and that they had been given opportunities to develop new skills ( $\mathrm{N}=447,47 \%)$.

For statements relating to Flexibility and Individual Need, the results showed that a very high proportion indicated agreement that their force was as flexible as they would like in terms of when and how long they volunteer $(\mathrm{N}=801,84 \%)$, with nearly two-thirds of respondents agreeing that they were given an opportunity to volunteer in an area of interest $(\mathrm{N}=596,63 \%)$.

Around half of respondents indicated agreement with statements relating to Feedback, in terms of being given an opportunity to provide feedback on their role $(\mathrm{N}=$ $489,52 \%)$ and satisfaction with the level of feedback on their performance $(\mathrm{N}=527$, $56 \%$ ). 


\section{INSERT TABLE 2 ABOUT HERE}

A chi-square test of independence was performed to examine the relationship between the results for the statements in Table 2 and self-reported morale, illustrated in Table 3. In order to conduct this analysis, the respondents who indicated 'Neither Agree nor Disagree' were excluded. Statements within the categories of Recognition, Appreciation and Fair Treatment, and Management and Supervision were observed to have the highest association on self-reported morale. The analysis revealed a medium strength of association for statements related to being treated fairly as a volunteer $\left(\chi^{2}\right.$ $(1)=174.932, p=<.001)$, satisfaction with the level of supervision received in providing personal and professional support $(\chi 2(1)=120.014, p=<.001)$, feeling like they had supported their local police force $\left(\chi^{2}(1)=114.180, p=<.001\right)$, and feeling appreciated by their police service for the work they had put in and impact they had $\operatorname{made}(\chi 2(1)=112.544, \mathrm{p}=<.001)$.

A medium strength of association was also found for statements relating to their view of whether the force was good at managing volunteers $(\chi 2(1)=79.023, p=$ $<.001)$, satisfaction with feedback on their performance $\left(\chi^{2}(1)=75.529, \mathrm{p}=<.001\right)$, whether their efforts as a volunteer were well recognised $\left(\chi^{2}(1)=82.863, p=<.001\right)$, receiving sufficient ongoing training to remain effective in their role as a volunteer $\left(\chi^{2}\right.$ $(1)=63.472, p=<.001)$, the force's understanding of the particular skills and experience they have and the opportunity to utilise these skills whilst volunteering ( $\chi^{2}$ $(1)=60.392, p=<.001)$, and whether they felt that they had made a difference to their community $\left(\chi^{2}(1)=56.461, \mathrm{p}=<.001\right)$. All other statements, whilst being statistically significant, were found to have a small strength of association on self-reported morale. 


\section{INSERT TABLE 3 ABOUT HERE}

\section{Discussion}

\section{Connection and Contribution}

The results show strength of association between PSV morale and a range of elements relating to their connection and contribution within the policing organisation. These include feelings that they had supported their local police force, were being treated fairly as a volunteer, were appreciated for the time they give and impact they made, were creating a difference in their community, and that their efforts as a volunteer were recognised. These findings resonate with those of Zhao et al. (2012, p. 43) who suggested that dimensions of connection and contribution may hold a salience for volunteers within community safety and criminal justice settings, where the work of the wider organisation and tasks undertaken by volunteers are at times focused on the "dark side of social life". In this context, volunteering activities may bring a less positive set of immediate rewards, and fewer opportunities to see the end result in the same manner that some other volunteering roles provide, thus amplifying the importance of feeling a connection within the organisation.

Whilst themes of contribution and connection remain little researched specifically in respect of PSVs, there is a body of literature beyond policing which explores the distinct but overlapping constructs of volunteer engagement, psychological contract, and organisational connectedness and commitment. Several studies have pointed to the impact of organisational connectedness on volunteer wellbeing, health and retention (e.g. Kramer 2001, Huynh et al. 2012a, 2012b, Walker et al. 2016), and identified the importance of organisational commitment and work engagement 
(Boezeman and Ellemers 2008, Vecina et al. 2013, Alfres et al. 2015). Stirling et al. (2011) found that relational aspects of psychological contract relating to the volunteering ethos of trust, network and belonging were key features in shaping the success of volunteer management practices and influencing volunteer sustainability.

Being helpful and contributing to service goals appeared significant in the motivations of many PSVs and recognition, appreciation and fair treatment were identified as being significant to PSV morale. This resonates with the findings of earlier research into PSV experience in Lancashire, which identified the importance of values, and of value-driven principles, as motivations for many of those who volunteer (Millie, 2016). It is imperative, therefore, that orientation and training processes, and subsequent support and management of volunteers, are effective through linking the ethos and work of volunteers to the priorities and mission of the organisation (Wisner et al. 2005). The survey results suggest police organisations need to pay greater attention to how PSVs are engaged in ways which achieve their 'connection' with the wider ethos and activities of the police, and which enable them to make a genuine contribution. These findings point to the importance of a positive, pro-active approach to volunteer management in which PSVs are able to see how their activities 'fit' within the totality of policing activity and feel appreciated for their inputs. This will help them to actively integrate and feel part of the wider policing team. Given the broader challenges of ambiguity, tensions, organisational culture, and peripheral status that surround PSV roles, the challenges of achieving connection and recognising contribution warrant particular attention. This is required at both operational and strategic level to support improvements in the experience of individual PSVs, and ensure that PSV programmes achieve these elements more generally within the overall corporate picture of police force direction and leadership. 


\section{Development, Training and Skills}

Survey statements relating to PSVs receiving sufficient ongoing training to remain effective in their role, the force's understanding of their skills and experience, and providing opportunities to utilise these all showed significant association with their morale as volunteers. This makes sense in the context of the discussion above: fully utilising the skills that volunteers bring, and providing opportunities to develop further are critical to supporting volunteers to make an effective contribution and feel connected within the organisation. Failing to do so shows an association with lower morale amongst PSVs. Processes of training, and recognising and engaging volunteer skills also carry a broader role in developing feelings of connection. Wider literature on volunteer experience points to training as a key element of the initial 'encounter phases' for new volunteers, and an early opportunity to begin establishing connection (Harvey et al. 2010). This reflects important dimensions for volunteers in terms of 'sense making' (Weick 1995), ‘meaning making' (Schnell and Hoof 2012), 'membership negotiation' (Castor and Jiter 2013, p. 89), and 'organisational socialisation' (Kramer 2013).

Saksida et al. (2016) conceptualised a model based upon 'role mastery', which impacts upon commitment to the volunteer organisation. They argue that 'role mastery' can be achieved primarily through effective training and positive practice opportunities, securing role clarity and self-efficacy amongst volunteers, and fostering supportive relationships and a 'valuing culture' between volunteers and paid staff. Iverson (2013, p. 45) developed thinking in respect of belonging and connection for volunteers, highlighting the importance that "the communicative enactment of belonging during training of volunteers" can play. Tasks that volunteers perform - even those that are limited in terms of complexity - together with volunteer 'career' events, training, induction and other opportunities to develop, offer important aspects of socialisation, 
and a sense of 'joining', 'connecting' and 'belonging'. The understanding of the particular skills volunteers have as well as an opportunity to utilise these skills whilst volunteering were found to be significant factors related to morale. Making greater effort to understand the skills that volunteers offer, and bringing a greater focus to developing and utilising these, would pay dividends to the police organisation in terms of participation and retention.

\section{Management, Support and Supervision}

Survey analysis showed a strong association between factors relating to management and supervision, and respondents' morale as volunteers. Satisfaction with the level of supervision received in providing personal and professional support and feedback on performance, together with a more general sense that their force is good at managing volunteers, were each significant in shaping volunteers' feelings of morale.

There appear to be challenges with delivering management and support of volunteers in police organisations. Britton and Knight (2016, p. 2) set out an aspirational vision that:

The police are recognised as being very good at leading, managing and supporting their volunteers. The ability to lead volunteers is seen as a critical capability for senior leaders in policing. Police organisations provide a great experience for those who volunteer with them. The cultures of police organisations are ones in which volunteers can grow, develop and flourish.

There is currently little published evidence on PSV support and experience, and the evidence presented in this article suggests that police organisations need to invest and develop their volunteering programmes to meet this aspiration. As the discussion 
earlier outlined, discrepancies between expectation and reality in volunteering roles are linked to morale. Failing to offer satisfying and rewarding volunteering roles that clearly contribute to business need - or, at the very least, managing expectations around what roles entail - can lead to lack of motivation and commitment from both organisation and volunteer, limited cultural acceptance of volunteers, and reputational risk for the police service (Bullock, 2017).

\section{Conclusion}

Findings from the national survey point both to the value of developing greater understandings of the role of PSVs, and the importance of identifying learning from this to positively impact upon their experiences in the future. Morale has been identified as an important factor for volunteers in terms of their feelings and attitudes towards their role, and intention to continue volunteering for the organisation. The survey highlighted a range of key influencers on PSV morale: the connection and contribution volunteers feel with and for the policing organisation, their experiences of training and skills appreciation and utilisation, and their management, support and supervision. Each of these factors exist against a changing strategic backdrop for policing, most notably in terms of the growing diversity of individuals who now play a role in law enforcement and community safety.

\section{Strategic Context and the Importance of Improving the Experience of Volunteering in Policing}

Despite being a feature of the policing landscape for over two decades, PSVs remain a relatively under-developed concept. Their roles are highly variable and inconsistent in terms of scale, activity, resourcing, and quality across forces. Their position is culturally ambiguous, viewed with ambivalence by leaders, officers, and staff in policing organisations, and rarely attract serious and sustained strategic attention and investment 
(Crawford 2008). As a result, the PSV programme in most forces lacks a defined and fully compelling vision for future development (Britton and Knight 2016). Whilst a national survey of this nature tends towards identifying broad areas for focus and improvement, the findings from this study do point to practical areas of change in managing and supporting PSVs.

The need to develop volunteers' feelings of connection and a sense of their contribution to the organisation is clear. This requires a focus on engaging, embedding, and socialising PSVs from the 'beginnings' of their volunteer experience to help them become integrated and aligned with the ethos of the organisation (or, indeed, challenge this ethos where necessary), and ensure that their motivations and skills are understood and reflected in volunteering opportunities. Police organisations need to give greater emphasis to volunteers understanding the outcomes and value of their volunteering, and feeling appreciated and recognised for what they do. 'Needs-based' and 'business-led' models which recruit volunteers to address clear organisational priorities, strengthening models of reward and recognition, and highlighting positive narratives about role, delivery and outcomes for PSVs across the police organisation, would contribute to this.

As Britton and Knight (2016 p. 4) asserted "any high-quality volunteering programme focuses on making the volunteering experience as good as it can possibly be... PSVs should be no different". They argue for a focus on developing inclusive cultures within police organisations, more innovative and imaginative approaches to using PSVs, and for strategic leaders to consider PSVs as a core, integrated, embedded, and critical element of policing. Approaches such as these would foster an environment in which volunteers are recognised, valued, and able to develop, and contribute to both existing operating models (in particular, community engagement and participatory models of prevention) and new directions in policing practice. 
While the development and expansion of volunteering within forces, particularly during times of fiscal restraint, may be attractive, it is clearly not a cost-free resource (Morgan 2012, Bullock 2014). The factors upon which effective use of volunteers relies that are outlined in this paper - access to adequate support resources, opportunities for development, a dedicated volunteer manager or coordinator, and processes of reward and recognition - each have costs attached. These costs, however, may not be readily forthcoming within organisations that traditionally favour task-focused and enforcement-based approaches, and are continually under pressure to make savings (Compact Code of Good Practice on Volunteering 2005, Wisner et al. 2005, Wilkins 2008, O’Neill 2014, Bullock, 2017).

If the future police workforce is going to involve volunteers - as legislative direction certainly seems to suggest - there is an even stronger imperative to focus on understanding and improving volunteer experience to ensure that both PSVs and policing organisations are getting the best out of all that volunteering can offer (Pepper 2014). Even if an upward trajectory of PSVs does not prevail, the 'here and now' namely the 8,000 individuals already undertaking a wide range of roles across policing alone merits much greater attention to understanding and improving their experiences than has been received to date.

\section{The Importance of a Growing Research Base on Police Support Volunteer}

\section{Experience}

To realise a bolder vision for future volunteering in policing requires a greater focus on better understanding the volunteer experience. Without establishing the evidence base 'foundation', opportunities to better utilise PSVs within policing may be wasted. This article has highlighted some key challenges to studying PSVs, which need to be recognised and embraced in the development of future research. The deficiencies in 
force approaches to collecting and managing relevant data need to be addressed as an enabler of research work across PSV populations. National approaches to data collection in terms of definition, standards, systematic collation and analysis offer a vital starting point here. Without these data improvement efforts, there will remain considerable uncertainty and guesswork in respect of the overall population of PSVs, their locations, demographics, diversity, roles, activity, and outcomes (Britton et al. 2016a).

Policy, practice and learning in relation to PSVs have emerged primarily at local level with limited steering, guidance or standards on a national scale. Whilst there are arguments for the vibrancy and responsiveness of a locally-led approach to the development of PSV programmes, there is also merit in capturing and disseminating learning and best practice to improve PSV experience at a national level. Future research needs to engage with the uncertainties and inconsistencies of definition, recognising the wide variation in PSV models in different forces and locations, and the range of distinct roles and activities encompassed under the overarching umbrella construct of the 'Police Support Volunteer'. This challenges both the generalisation of findings from national data into local settings, and of research conducted at force level across other areas. Future studies need to develop further understandings of issues at a whole population level and more in-depth sensitive insights around experiences within a local context.

Establishing a greater appreciation of who volunteers and the nature of their participation would help to develop more sophisticated and nuanced research models across the diversity of experiences. The future research agenda needs to be sensitive to variety and difference, and avoid over-simplifying concepts of the PSV experience, pointing instead to a range of experiences. Such research models need a 'what works' 
ethos which seeks to develop research for a purpose: to build an evidence-based understanding of how to improve experiences, which in turn can have a practical translation and application both for those who volunteer in policing, and those within forces who are responsible for their support and management. Finally, future data collection and research efforts should be anchored around a commitment to hearing 'the voice' of police volunteers. This is a voice that is seldom heard, but one that could offer great insight and value to wider debates around policing and police reform.

\section{Acknowledgements}

The authors would like to acknowledge the support of North Yorkshire Police, who commissioned and managed the dissemination process for the survey. We further wish to acknowledge the support provided in the development of the survey by a range of agencies across the national Citizens in Policing Community of Practice.

\section{References}

Alfres, K., Shantz, A. and Saksida, T., 2015. 'Committed to Whom? Unraveling How

Relational Job Design Influences Volunteers' Turnover Intentions and Time Spent Volunteering'. VOLUNTAS: International Journal of Voluntary and Nonprofit Organizations, 26 (6), 2479-2499.

Allison, L., Okun, M. and Dutridge, K., 2002. 'Assessing Volunteer Motives: A Comparison of an Open-ended Probe and Likert Rating Scales'. Journal of Community and Applied Social Psychology, 12 (4), 243-255.

Boezeman, E. and Ellemers, N., 2008. 'Volunteer Recruitment: The Role of Organizational Support and Anticipated Respect in Non-Volunteers' Attraction to Charitable Volunteer Organizations'. Journal of Applied Psychology, 93 (5), 10131026. 
Britton, I. and Callender, M., 2018. 'Strategic Direction and Leadership in the Special Constabulary'. In: K. Bullock and A. Millie, eds. The Special Constabulary: Historical Context, International Comparisons and Contemporary Themes. Abingdon: Routledge. Britton, I. and Knight, L., 2016. 2030 Vision: Specials and Police Support Volunteers At the Heart of Policing Reform. Northampton: Institute for Public Safety, Crime and Justice.

Britton, I., Knight, L. and Maloney, D., 2016a. Citizens in Policing National Benchmarking Exercise: Phase One Report. Northampton: Institute for Public Safety, Crime and Justice.

Britton, I., Callender, M. and Cole, S., 2016b. National Survey of Special Constables and Police Support Volunteers: Initial Findings Report. Northampton: Institute for Public Safety, Crime and Justice.

Brudney, J. and Meijs, L., 2014. 'Models of Volunteer Management: Professional Volunteer Program Management in Social Work'. Human Service Organizations: Management, Leadership and Governance, 38 (3), 297-309.

Bullock, K., 2017. 'Shoring Up the Home Guard? Reflections on the Development and Deployment of Police Support Volunteer Programmes in England and Wales'. Policing and Society, 27(4), 341-357.

Bullock, K., 2014. Citizens, Community and Crime Control. Basingstoke: Palgrave Macmillan.

Bullock, K. and Leeney, D., 2014. 'On matters of balance: an examination of the deployment, motivation and management of the Special Constabulary'. Police and Society: An International Journal of Research and Policy, 26 (5), 483-502.

Bullock, K. and Leeney, D., 2013. 'Participation, 'Responsivity' and Accountability in Neighbourhood Policing'. Criminology and Criminal Justice, 13 (2), 199-214. 
Cabinet Office, 2008. Excellence and fairness: Achieving world class public services, London: HMSO.

Carr, P., 2012. 'Citizens, Community and Crime Control: The Problems and Prospects for Negotiated Order'. Criminology and Criminal Justice, 12 (4), 397-412.

Casey, L., 2008. Engaging Communities in Fighting Crime, Cabinet Office: London. Castor, T. and Jiter, M., 2013. 'Learning by the "Seat of Your Pants": The Socialization of Nonprofit Board Members'. In: M. Kramer, L. Lewis and L. Gossett, Eds. Volunteering and Communication: Studies from Multiple Contexts. New York, NY: Peter Lang, 85-104.

Citizens in Policing Community of Practice, 2016. Citizens in Policing: National Strategy 2016-2019, London: National Police Chiefs' Council.

Cnaan, R. and Cascio, T., 1998. 'Performance and Commitment Issues in Management of Volunteers in Human Service Organizations'. Journal of Social Service Research, 24 (3-4), 1-37.

Compact, 2005. Volunteering: Compact Code of Good Practice, Birmingham:

Commission for the Compact.

Cosgrove, F., 2016. 'II wannabe a copper': The engagement of Police Community Support officers with the dominant police occupational culture'. Criminology and Criminal Justice, 16 (1), 119-138.

Crawford, A., 2008. 'Plural Policing in the UK: Policing Beyond the Police'. In: T. Newburn, Ed. Handbook of Policing $2^{\text {nd }}$ Edition. Cullompton: Willan Publishing, 147181.

Emsley, C., 1996. The English Police: A Political and Social History, London: Longman. 
Evans, L., 1997. 'Understanding Teacher Morale and Job Satisfaction'. Teaching and Teacher Education, 13(8), 831-845.

Finnegan, A. and Brewis, G., 2012. The Volunteering England Archive: An Overview and Historical Background, London: London School of Economics.

Gaskin, K. and Smith, D., 1995. 'A New Civic Europe? A Study of the Extent and Role of Volunteering', London: National Centre for Volunteering (NCVO).

Giangrande, R., Haldenby, A., Lundy, L., Parsons, L., Thornton, D. and Truss, E., 2008. The Lawful Society, London: Reform.

Gill, M. and Mawby, R., 1990. A Special Constable: A Study of the Police Reserve, Aldershot: Avebury.

Gravelle, J. and Rogers, C., 2009a. 'The Economy of Policing - The Impact of the Volunteer'. Policing: A Journal of Policy and Practice, 4 (1), 56-63.

Gravelle, J. and Rogers, C., 2009b. 'Your Country Needs You! The Economic Viability of Volunteers in the Police'. Safer Communities, 8 (3), 34-38.

Harvey, J., Wheeler, A., Halbesleben, J. and Buckley, M., 2010. 'How did you figure that out? Employee Learning during Socialisation'. In: H. Liao, J. Martocchio and A. Joshi, Eds. Research in Personnel and Human Resources Management, 29, 167200.Huynh, J., Metzer, J. and Winefield, A., 2012a. 'Engaged or connected? A perspective of the motivational pathway of the job demands-resources model in volunteers working for non-profit organizations'. VOLUNTAS: International Journal of Voluntary and Nonprofit Organizations, 23 (4), 870-898.

Huynh, J., Metzer, J. and Winefield, A., 2012b. 'Validation of the Four-Dimensional Connectedness Scale in a Multisample Volunteer Study: A Distinct Construct from Work Engagement and Organisational Commitment'. VOLUNTAS: International Journal of Voluntary and Nonprofit Organizations, 23, 1056-1082. 
Iverson, J., 2013. 'Communicating Belonging: Building Communities of Expert Volunteers'. In: M. Kramer, L. Lewis and L. Gossett, Eds. Volunteering and Communication: Studies from Multiple Contexts. New York, NY: Peter Lang, 45-64. Jamison, I., 2003. 'Turnover and Retention Among Volunteers in Human Service Agencies'. Review of Public Personnel Administration, 23 (2), 114-132. Johnston, L., 2003. 'From 'Pluralisation' to the 'Police Extended Family': Discourses on the Governance of Community Policing in Britain'. International Journal of the Sociology of Law, 31 (3), 185-204.

Jones, T. and Newburn, T., 2006 'Understanding Plural Policing'. In: T. Jones and T. Newburn, Eds. Plural Policing: A Comparative Perspective. London: Routledge, 1-11. Kramer, R., 2001. 'Identity and Trust in Organizations: One anatomy of a productive but problematic relationship'. In: M. Hogg and D. Terry, Eds. Social Identity Processes and Organizational Contexts. Hove: Psychology Press, 167-179.

Kramer, M., 2013. 'The Socialization of Community Choir Members: A Comparison of New and Continuing Volunteers'. In: M. Kramer, L. Lewis and L. Gossett, Eds. Volunteering and Communication: Studies from Multiple Contexts. New York, NY: Peter Lang, 65-86.

Loftus, B., 2010. 'Police Occupational Culture: Classic Themes, Altered Times'. Policing and Society, 20 (1), 1-20.

Meijs, L. and Ten Hoorn, E., 2008. 'No “one best” volunteer management and organizing: Two fundamentally different approaches'. In: M. Liao-Troth, Ed. Challenges in volunteer management. Charlotte, NC: Information Age, 29-50. Millie, A. (2016) Volunteering within the Police: Experiences of Special Constables and Police Support Volunteers. Lancashire: Lancashire Constabulary/Edge Hill University. 
Millie, A. and Bullock, K., 2012. 'Re-imagining Policing Post-Austerity'. British Academy Review, 19, 16-18.

Morgan, R., 2012. 'Crime and Justice in the 'Big Society'. Criminology and Criminal Justice, 12 (5), 463-481.

Myhill, A., 2006. Community Engagement in Policing: Lessons from the Literature. London: NPIA.

Myhill, A. and Bradford, B., 2013. 'Overcoming Cop Culture? Organisational Justice and Police Officers' Attitudes Toward the Public'. Policing: An International Journal of Police Strategies and Management, 36 (2), 338-356.

O’Neill, M., 2014. 'Ripe for the Chop or the Public Face of Policing? PCSOs and Neighbourhood Policing in Austerity'. Policing: A Journal of Policy and Practice, 8 (3), 265-273.

Paull, M., 2002. 'Reframing volunteer management: A view from the West'. Australian Journal on Volunteering, 7 (1), 21-27.

Pepper, I., 2014. 'Do Part-time Volunteer Police Officers Aspire to be Regular Police Officers?'. The Police Journal: Theory, Practice and Principles, 87 (2), 105-113. Pepper, I. and Wolf, R., 2015. 'Volunteering to Serve: An international comparison of volunteer police officers in a UK North East Police Force and a US Florida Sheriff's Office'. The Police Journal: Theory, Practice and Principles, 88 (3), 209-19. Paoline, E., 2003. 'Taking stock: Toward a richer understanding of police culture'. Journal of Criminal Justice, 31 (3), 199-214.

Phillips, S., 2013. 'Using Volunteers in Policing: A Force Field Analysis of American Supervisors'. The Police Journal, 86 (4), 289-306. 
Phillips, S. and Terrell-Orr, A., 2013. 'Attitudes of Police Supervisors: Do Volunteers Fit into Policing?'. Policing: An International Journal of Police Strategies and Management, 36 (4), 683-701.

Reiner, R., 2010. The Politics of the Police, Oxford, Oxford University Press.

Ren, L., Zhao, J., Lovrich, N. and Gaffney, M., 2006. 'Participation in Community Crime Prevention: Who Volunteers for Police Work?'. Policing: An International Journal of Police Strategies and Management, 29 (3), 464-481.

Rochester, C., 1999. 'One size does not fit all: Four models of involving volunteers in voluntary organizations'. Voluntary Action, 1 (2), 47-59.

Rochester, C., Paine, A. and Howlett, S. 2010. 'Volunteering and Society in the 21st Century’, Basingstoke: Palgrave Macmillan.

Rogers, C., 2012. Plural Policing: Theory and Practice, Bristol: Policy Press.

Saksida, T., Alfes, K. and Shantz, A., 2016. 'Volunteer role mastery and commitment: can HRM make a difference?'. International Journal of Human Resource Management, $28(14), 1-23$.

Schnell, T. and Hoof, M., 2012. 'Meaningful commitment: finding meaning in volunteer work'. Journal of Beliefs and Values, 33 (1), 35-53.

Sherr, M. 2008. Social work with volunteers, Chicago, IL: Lyceum Books.

Shin, S. and Kleiner, B., 2003. 'How to Manage Unpaid Volunteers in Organisations'. Management Research News, 26 (2/3/4), 63-71.

Steden, R., van Caem, R. and Boutellier, H., 2011. 'The 'Hidden Strength' of Active Citizenship: The Involvement of Local Residents in Public Safety Projects'. Criminology and Criminal Justice, 11 (5), 433-450.

Stenning, P., 2009. 'Governance and Accountability in a Plural Policing Environment The Story So Far'. Policing: A Journal of Policy and Practice, 3 (1), 22-33. 
Stenning, P. and Shearing, C., 2015. 'Privatisation, Pluralisation and the Globalisation of Policing'. Australian Institute of Police Management Public Safety Leadership Research Focus, 3 (1), 1-8.

Stirling, C., Kilpatrick, S. and Orpin, P., 2011. 'A psychological contract perspective to the link between non-profit organizations' management practices and volunteer sustainability'. Human Resource Development International, 14 (3), 321-336.

Studer, S., 2016. 'Volunteer Management'. Nonprofit and Voluntary Sector Quarterly, $45(4), 688-714$.

Unison, 2014. Home Guard of Police Support Volunteers to fill in for Staff Cuts, London: Unison.

Van Caem, B., Steden, R., Boutellier, H. and Stokkom, B., 2013. 'Community Policing 'Light': On Proximity and Distance in Relationships between Neighbourhood Coordinators and Citizens'. Policing: A Journal of Policy and Practice, 7 (3), 263-272. Vecina, M., Fuertes, F., Marzana, D. and Marta, E., 2013. 'Volunteer engagement and organizational commitment in non-profit organizations: What makes volunteers remains within organizations and feel happy?'. Journal of Community Psychology, 41(3), 291302.

Walker, A., Accadia, R and Costa, B., 2016. 'Volunteer retention: The importance of organisational support and psychological contract breach'. Journal of Community Psychology, 44 (8), 1059-1069.

Weakliem, D. and Frenkel, S., 2006. Morale and Workplace Performance. Work and Occupations, 33 (3), 335-361.

Weick, K., 1995. Sensemaking in organizations. Thousand Oaks, CA: Sage.

Wilkins, T., 2008. 2008 Police Support Volunteer (PSV) Questionnaire, London: College of Policing. 
Wisner, P., Stringfellow, A., Youngdahl, W. and Parker, L., 2005. 'The Service

Volunteer - Loyalty Chain: An Exploratory Study of Charitable Not-For-Profit Service Organisations'. Journal of Operations Management, 23 (2), 143-161.

Zedner, L., 2003. 'Too much Security?'. International Journal of the Sociology of Law, $31(3), 155-184$.

Zhao, J., Gibson, C., Lovrich, N. and Gaffney, M., 2012. 'Participation in Community Crime Prevention: Are Volunteers More or Less Fearful of Crime than other Citizens?'. Journal of Crime and Justice, 25 (1), 41-61.

Zimmeck, M., 2012. 'Government and Volunteering: Towards a History of Policy and Practice'. In: C. Rochester, A. Ellis Paine and S. Howlett, Eds. Volunteering and Society in the 21st Century, Basingstoke: Palgrave Macmillan. 
Table 1. Basic demographic characteristics of study participants $(n=1,002)$

\begin{tabular}{|c|c|c|}
\hline Gender $(n=992)$ & $n$ & $\%$ \\
\hline Female & 452 & $46 \%$ \\
\hline Male & 540 & $54 \%$ \\
\hline \multicolumn{3}{|l|}{ Ethnicity $(n=982)$} \\
\hline Asian & 32 & $3 \%$ \\
\hline Black & 10 & $1 \%$ \\
\hline Mixed ethnicity & 9 & $1 \%$ \\
\hline White & 927 & $94 \%$ \\
\hline Other & 4 & $0 \%$ \\
\hline \multicolumn{3}{|l|}{ Age $(n=958)$} \\
\hline $18-24$ & 83 & $9 \%$ \\
\hline $25-29$ & 38 & $4 \%$ \\
\hline $30-34$ & 25 & $3 \%$ \\
\hline $35-39$ & 27 & $3 \%$ \\
\hline $40-44$ & 47 & $5 \%$ \\
\hline $45-49$ & 47 & $5 \%$ \\
\hline $50-54$ & 86 & $9 \%$ \\
\hline $55-59$ & 84 & $9 \%$ \\
\hline $60-64$ & 128 & $13 \%$ \\
\hline $65-69$ & 189 & $20 \%$ \\
\hline $70-74$ & 144 & $15 \%$ \\
\hline $75-79$ & 43 & $4 \%$ \\
\hline $80+$ & 17 & $2 \%$ \\
\hline \multicolumn{3}{|l|}{ Length of service $(n=941)$} \\
\hline Less than 6 months & 131 & $14 \%$ \\
\hline $6<12$ months & 63 & $7 \%$ \\
\hline 1 year but less than 2 years & 161 & $17 \%$ \\
\hline 2 years but less than 5 years & 287 & $30 \%$ \\
\hline 5 years but less than 10 years & 233 & $25 \%$ \\
\hline 10 years but less than 20 years & 57 & $6 \%$ \\
\hline 20 years or more & 9 & $1 \%$ \\
\hline
\end{tabular}


Table 2. Police Support Volunteer Survey Results

\begin{tabular}{|c|c|c|c|}
\hline & $\begin{array}{l}\text { Agree } \\
n(\%)\end{array}$ & $\begin{array}{l}\text { Neither agree } \\
\text { nor disagree }\end{array}$ & Disagree \\
\hline \multicolumn{4}{|l|}{ Management and Supervision } \\
\hline $\begin{array}{l}\text { I am satisfied with the level of supervision I } \\
\text { receive in providing me with the personal and } \\
\text { professional support I need }\end{array}$ & $686(72 \%)$ & $165(17 \%)$ & $100(11 \%)$ \\
\hline The force is good at managing volunteers & $532(56 \%)$ & $275(29 \%)$ & $148(16 \%)$ \\
\hline I like and enjoy the work I have been asked to do & $872(90 \%)$ & $72(8 \%)$ & $21(2 \%)$ \\
\hline \multicolumn{4}{|l|}{ Training } \\
\hline $\begin{array}{l}\text { I received the initial training I required to be } \\
\text { effective when I began my volunteering role }\end{array}$ & $659(69 \%)$ & $187(20 \%)$ & $107(11 \%)$ \\
\hline $\begin{array}{l}\text { I am receiving sufficient ongoing training to } \\
\text { remain effective in my role as a volunteer }\end{array}$ & $506(53 \%)$ & $299(31 \%)$ & $146(15 \%)$ \\
\hline \multicolumn{4}{|l|}{ Recognition, Appreciation and Fair Treatment } \\
\hline My efforts as a volunteer are well recognised & $706(74 \%)$ & $193(20 \%)$ & $56(6 \%)$ \\
\hline $\begin{array}{l}\text { I feel appreciated by the police service for the } \\
\text { work I put in and the impact I make }\end{array}$ & $706(74 \%)$ & $190(20 \%)$ & $62(7 \%)$ \\
\hline I feel that I am treated fairly as a volunteer & $836(88 \%)$ & $102(11 \%)$ & $17(2 \%)$ \\
\hline \multicolumn{4}{|l|}{ Making a difference to the community } \\
\hline I feel I have made a difference to my community & $605(63 \%)$ & $294(30 \%)$ & $69(7 \%)$ \\
\hline $\begin{array}{l}\text { I feel I have helped to tackle crime/anti-social } \\
\text { behaviour in my community }\end{array}$ & $370(40 \%)$ & $358(38 \%)$ & $210(22 \%)$ \\
\hline I feel I have supported my local Police Service & $869(89 \%)$ & $80(8 \%)$ & $27(3 \%)$ \\
\hline \multicolumn{4}{|l|}{ Skill Recognition and Development } \\
\hline $\begin{array}{l}\text { The force understands the particular skills and } \\
\text { experience I bring and has given me } \\
\text { opportunities to utilise the full range of my skills } \\
\text { and experience whilst volunteering }\end{array}$ & $497(53 \%)$ & $272(29 \%)$ & $173(18 \%)$ \\
\hline $\begin{array}{l}\text { I have been given opportunities to develop new } \\
\text { skills and abilities }\end{array}$ & $447(47 \%)$ & $309(33 \%)$ & $190(20 \%)$ \\
\hline \multicolumn{4}{|l|}{ Flexibility and Individual Need } \\
\hline $\begin{array}{l}\text { My Police Service is as flexible as I would like it } \\
\text { to be about when and how long I volunteer }\end{array}$ & $801(84 \%)$ & $114(12 \%)$ & $36(4 \%)$ \\
\hline $\begin{array}{l}\text { I am given the opportunity to volunteer in the } \\
\text { areas I am interested in }\end{array}$ & $596(63 \%)$ & $233(25 \%)$ & $120(13 \%)$ \\
\hline \multicolumn{4}{|l|}{ Feedback } \\
\hline $\begin{array}{l}\text { I've been given the opportunity to provide } \\
\text { feedback on my role }\end{array}$ & $489(52 \%)$ & $242(26 \%)$ & $214(23 \%)$ \\
\hline $\begin{array}{l}\text { I am satisfied with the level of feedback I've } \\
\text { received on my performance }\end{array}$ & $527(56 \%)$ & $282(30 \%)$ & $135(14 \%)$ \\
\hline \multicolumn{4}{|l|}{ Morale } \\
\hline I would describe my morale as being good & $833(88 \%)$ & $76(8 \%)$ & $41(4 \%)$ \\
\hline
\end{tabular}


Table 3. Associations of Police Support Volunteers Responses with Morale

\begin{tabular}{|c|c|c|c|c|c|c|c|}
\hline & $\mathrm{N}$ & $\begin{array}{l}\% \text { that agreed with } \\
\text { the statement whose } \\
\text { morale is good }\end{array}$ & $\begin{array}{l}\% \text { that disagreed with } \\
\text { the statement whose } \\
\text { morale is good }\end{array}$ & Phi & $\chi^{2}$ & $\mathrm{df}$ & $\mathrm{p}$ \\
\hline \multicolumn{8}{|l|}{ Management and Supervision } \\
\hline $\begin{array}{l}\text { I am satisfied with the level of supervision I } \\
\text { receive in providing me with the personal and } \\
\text { professional support I need }\end{array}$ & 725 & $95 \%$ & $70 \%$ & .407 & 120.014 & 1 & $\leq .001 *$ \\
\hline The force is good at managing volunteers & 624 & $96 \%$ & $78 \%$ & .356 & 79.023 & 1 & $\leq .001$ \\
\hline $\begin{array}{l}\text { I like and enjoy the work I have been asked to } \\
\text { do }\end{array}$ & 816 & $91 \%$ & $57 \%$ & .259 & 54.866 & 1 & $\leq .001 *$ \\
\hline \multicolumn{8}{|l|}{ Training } \\
\hline $\begin{array}{l}\text { I received the initial training I required to be } \\
\text { effective when I began my volunteering role }\end{array}$ & 694 & $92 \%$ & $78 \%$ & .221 & 33.978 & 1 & $\leq .001 *$ \\
\hline $\begin{array}{l}\text { I am receiving sufficient ongoing training to } \\
\text { remain effective in my role as a volunteer }\end{array}$ & 592 & $94 \%$ & $82 \%$ & .327 & 63.472 & 1 & $\leq .001$ \\
\hline \multicolumn{8}{|l|}{$\begin{array}{l}\text { Recognition, Appreciation and Fair } \\
\text { Treatment }\end{array}$} \\
\hline My efforts as a volunteer are well recognised & 701 & $93 \%$ & $72 \%$ & .344 & 82.863 & 1 & $\leq .001^{*}$ \\
\hline $\begin{array}{l}\text { I feel appreciated by the police service for the } \\
\text { work I put in and the impact I make }\end{array}$ & 711 & $94 \%$ & $71 \%$ & .398 & 112.544 & 1 & $\leq .001 *$ \\
\hline I feel that I am treated fairly as a volunteer & 787 & $92 \%$ & $54 \%$ & .471 & 174.932 & 1 & $\leq .001^{*}$ \\
\hline \multicolumn{8}{|l|}{ Making a difference to the community } \\
\hline $\begin{array}{l}\text { I feel I have made a difference to my } \\
\text { community }\end{array}$ & 613 & $92 \%$ & $81 \%$ & .303 & 56.461 & 1 & $\leq .001^{*}$ \\
\hline $\begin{array}{l}\text { I feel I have helped to tackle crime/anti-social } \\
\text { behaviour in my community }\end{array}$ & 528 & $91 \%$ & $85 \%$ & .125 & 8.273 & 1 & $\leq .005$ \\
\hline I feel I have supported my local Police Service & 813 & $91 \%$ & $63 \%$ & .375 & 114.180 & 1 & $\leq .001^{*}$ \\
\hline
\end{tabular}




\begin{tabular}{|c|c|c|c|c|c|c|c|}
\hline \multicolumn{8}{|l|}{ Skill Recognition and Development } \\
\hline $\begin{array}{l}\text { The force understands the particular skills and } \\
\text { experience I bring and has given me } \\
\text { opportunities to utilise the full range of my } \\
\text { skills and experience whilst volunteering }\end{array}$ & 615 & $96 \%$ & $79 \%$ & .313 & 60.392 & 1 & $\leq .001$ \\
\hline $\begin{array}{l}\text { I have been given opportunities to develop new } \\
\text { skills and abilities }\end{array}$ & 581 & $94 \%$ & $82 \%$ & .261 & 39.444 & 1 & $\leq .001$ \\
\hline \multicolumn{8}{|l|}{ Flexibility and Individual Need } \\
\hline $\begin{array}{l}\text { My Police Service is as flexible as I would like } \\
\text { it to be about when and how long I volunteer }\end{array}$ & 754 & $89 \%$ & $82 \%$ & .204 & 31.290 & 1 & $\leq .001^{*}$ \\
\hline $\begin{array}{l}\text { I am given the opportunity to volunteer in the } \\
\text { areas I am interested in }\end{array}$ & 654 & $92 \%$ & $80 \%$ & .245 & 39.296 & 1 & $\leq .001 *$ \\
\hline \multicolumn{8}{|l|}{ Feedback } \\
\hline $\begin{array}{l}\text { I've been given the opportunity to provide } \\
\text { feedback on my role }\end{array}$ & 635 & $95 \%$ & $80 \%$ & .285 & 51.432 & 1 & $\leq .001$ \\
\hline $\begin{array}{l}\text { I am satisfied with the level of feedback I've } \\
\text { received on my performance }\end{array}$ & 607 & $96 \%$ & $77 \%$ & .353 & 75.529 & 1 & $\leq .001 *$ \\
\hline
\end{tabular}

* Fisher's Exact Test reported 